\title{
SUBLIME: UM VAZIO PREGNADO
}

Maria Costa de Araujo ${ }^{1}$

Silvana B. Macedo ${ }^{2}$

\section{RESUMO}

Este artigo aborda os aspectos históricos dos conceitos de sublime e de vazio, e reflete sobre possíveis maneiras de pensá-los com relação a projetos artísticos na contemporaneidade. Os projetos estudados lidam com a mediação da ciência e tecnologia na relação humana com a natureza, e sua articulação na arte. Investigam-se, portanto, trabalhos artísticos que fazem uso de aparatos tecnológicos para interagir com animais e meio ambiente. Entre os projetos abordados, estão: desenhos e fotografias de Tim Knowles, projeto The Greenhouse and the Shed, de Gilles Bruni e Marc Batarit, projeto Cads - Cricket-Activated Defense System, PigeonBlog de Beatriz da Costa, Russian Beluga Project, de Jim Nollman.

PALAVRAS-CHAVE: Sublime, Vazio, Arte Contemporânea.

"A arte consiste em ocultar a arte" (OVÍDIO, apud TARKOVSKI, p.52).

\footnotetext{
${ }^{1} 1$ Universidade do Estado de Santa Catarina - UDESC - Centro de Artes Bolsista Voluntária - Acadêmica - Bacharelado em Artes Plásticas E-mail: maria.arte.araujo@gmail.com

${ }^{2}$ Universidade do Estado de Saanta Catarina - UDESC -Centro de Artes Coordenadora de Pesquisa - Profa. Dra.

$\mathrm{PhD}$ in Fine Arts, Northumbria University, UK

Pós-doutorado UCS

E-mail: silvana_b_macedo@hotmail.com
} 
Muitos artistas hoje se unem a cientistas, pesquisadores, ecologistas, engenheiros, biólogos, entre outros parceiros, para expressar suas preocupações com o meio ambiente, tornando-as talvez mais visíveis e reais. Com o apoio de tecnologias oferecidas por outras disciplinas ou áreas do saber, artistas buscam tornar suas preocupações mais evidentes ao espectador, aguçando suas sensações, alterando percepções, ao apresentar coisas que seria impossível perceber sem o aparelho tecnológico e sem essa mescla com outras áreas de conhecimento.

Abordaremos no decorrer deste artigo a maneira como os artistas têm explorado temas que podem ser relacionados ao conceito de sublime. Ao longo da história da arte, o conceito de sublime esteve associado à figuração; advindo a abstração, mais recentemente, pode-se encontrá-lo em trabalhos que trazem em si um "vazio enigmático", numa ânsia de refletir a complexidade de nossos dias.

O sublime, como o vazio, é um conceito emblemático, e, por sua complexidade, não pode ser definido de forma direta, estável ou simplificada. Considerando-se suas nuanças conflitantes e paradoxais, como ressalta Guy Amado, o sublime é um "conceito da teoria estética que está longe de comportar uma acepção definida e estanque" (AMADO, 2006, p.18).

A origem do termo é latina: sublimis. Mais corriqueiramente designa algo excelso, eminente ou sumamente elevado, e se aplica tanto a fenômenos naturais quanto a ações humanas, explica Adolfo S. Vázquez, professor da Universidade Nacional Autônoma do México, complementando que "neste sentido, são sublimes um furacão, uma catarata, o céu estrelado ou o imenso deserto, assim como o comportamento dos homens que arriscam ou sacrificam sua vida por uma causa nobre" (VÁZQUEZ, 1999, p. 231). Argumentos esses endossados por vários filósofos e pesquisadores da área.

Philip Shaw, da Universidade de Leicester, ao pesquisar os aspectos históricos

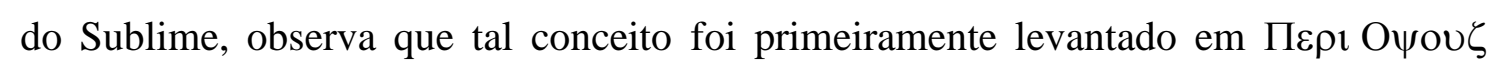
(Sobre o sublime), um tratado estético atribuído ao grego Dionysius Longinus no século I, traduzido por Nicolas Boileau em 1674 como Du Sublime. "Para Longinus, o discurso do sublime, seja oratória política ou verso épico, trabalha para superar os poderes racionais de sua audiência e persuadi-los da eficácia de uma idéia, por meio de força retórica absoluta (SHAW, 2006, p. 4-5)3. Portanto, para os gregos, o conceito do

\footnotetext{
3 "For Longinus, the discourse of the sublime, whether in political oratory or in epic verse, works to overcome the rational powers of its audience, persuading them of the efficacy of an idea by means of sheer rhetorical force".
} 
sublime é pensado em termos de idéias ou ações humanas, ao invés de se referir a fenômenos naturais.

Muitos séculos depois, o conceito do Sublime foi associado à pintura de paisagem dos artistas Românticos, como Gaspar David Friedrich, Joseph Mallord, William Turner e Samuel Palmer, citando apenas alguns que viram na paisagem um meio de representar o transcendental, o enigmático, a "inquietante percepção do tempo e de sua passagem” (BECKETT, 2002, p. 271).

Transpondo esta longa tradição que o conceito do sublime carrega para a contemporaneidade, vamos examinar projetos de artistas que lidam com o meio ambiente em seus projetos. No trabalho do contemporâneo Tim Knowles ${ }^{4}$ ocorre uma desaparição, a mão do artista não desenha. Knowles prende canetas nas pontas dos galhos de árvores, suspendendo papéis, para que o movimento dos galhos, ditado pelo vento, componha seu desenho. Knowles dá "voz" ao vento para que, através das árvores, se comunique. Cada tipo de árvore produz diferentes marcas ou inscrições. Os variados tipos de árvores, diferentes brisas, distintos lugares, tudo influencia no trabalho final. $\mathrm{O}$ artista trabalha, desta forma, com a imprevisibilidade, a surpresa do por vir, em torno de um mistério.

Knowles expõe a relação homem/ natureza, atentando para esta convivência. O artista abre assim uma porta para o vazio, tornando o indizível da obra uma fonte de conexão entre a natureza e o espectador. $\mathrm{O}$ vazio ao qual nos referimos aqui não é um vazio niilista, mas um vazio prenhe de possíveis significados, que possibilita uma parada na percepção corriqueira que decifra uma mensagem rapidamente, para logo se voltar para outra coisa. O trabalho convida para uma contemplação ou uma observação mais acurada da complexa relação entre tantos elementos que produziram aquela imagem: o vento, a arvore, o artista e o contexto no qual as imagens são apresentadas. A transposição deste contexto natural, paisagem, para o contexto cultural da galeria, é o trabalho do artista, e não necessariamente o traço do desenho feito pela sua mão.

Será o inglês Edmund Burke (1729-97) na sua obra Indagação filosófica sobre a origem de nossas idéias acerca do sublime e do belo, de 1757, que fará o primeiro estudo sistemático do sublime como categoria estética. Os pesquisadores atuais utilizam-se de suas reflexões para mostrar como esse conceito aparece hoje.

\footnotetext{
${ }^{4}$ Rockeby Gallery. Disponível em: http://www.rokebygallery.com/matrix_engine/content.php?page_id=944\&image=1174 Acessado em: $30 / 09 / 07$
} 
Márcio Seligmann-Silva nos fala de dois Sublimes: o "sensualista" de Burke e o "espiritualista" de Mendelssohn. Ele diz que, para Burke, o sublime não pode ser conceitualizado, pois se trata do inominável, seria a manifestação do ilimitado e mostraria que a dor e o perigo, ligados à preservação do individuo, são fontes do Sublime, sendo que o terror seria uma das mais fortes emoções que a mente humana é capaz de sentir. De acordo com Burke:

Nenhuma paixão despoja tão completamente o espírito de toda a sua faculdade de agir e de raciocinar quanto o medo. Pois este, sendo um pressentimento de dor ou de morte, atua de maneira semelhante à dor real. (BURKE, 1993. p. 65/66).

Segundo Seligmannn-Silva, Burke mostra que sentimos certo deleite nos infortúnios e dores reais dos outros. $\mathrm{O}$ "real enquanto manifestação da morte nos arrebata com uma força irresistível e impede nossa mente de raciocinar" (SILVA, 2005 p. 34). Burke reflete sobre como o sublime emerge da ausência: "Todas as privações em geral são grandiosas, porque são todas terríveis: vazio, trevas, solidão e silêncio" (BURKE, 1993. p. 76).

É também com privação que Gilles Bruni e Marc Batarit nos confrontam em The Greenhouse and the Shed ${ }^{5}$. Mostram que com pouco se consegue muito, inclusive casa e comida. Apropriam-se de árvores caídas, mostrando que elas ainda têm utilidade, e criam um habitat quase impensável nos dias de hoje.

Desde 1980 esses artistas colaboradores produzem instalações externas e experimentais, combinando agricultura, ecologia, arquitetura e fotografia. Seus projetos impõem uma ordem temporária e uma forma escultural no local da intervenção, interferindo naquilo que encontram, propondo novas possibilidades, convidando a ir além do convencional e buscar alternativas justas para a natureza e para o ser humano.

Após a seleção do local, Bruni e Babarit iniciam um processo temporário de apropriação, uma breve tomada ou domesticação do local. Usando o que eles encontram lá, partem para interpretá-lo, considerando toda sua história - em termos ecológicos depois alterando e adaptando a ordem das coisas e posterior crítica dos aspectos das intervenções.

\footnotetext{
${ }^{5}$ (A estufa e o barracão)
}

Greenmuseum.org. Disponível em: http://greenmuseum.org/content/artist_index/artist_id-90.html Acessado em: 23/20/07 
O vazio desvela seu dicionário secreto, tamanha nossa inoperância frente às questões meio-ambientais. O que dizer? O que fazer? Qual pode ser nossa atitude frente às coisas que esse vazio deixa soçobrar?

O outro conceito de sublime de que nos fala Seligmann-Silva é o sublime "espiritualista" de Moses Mendelssohn, considerado um dos principais teóricos do conceito na Alemanha (1758). Embora suas reflexões se aproximem das de Burke, Mendelssohn pensa o sublime numa "categoria que tende mais a ser tratada como uma manifestação do infinito enquanto uma entidade superior, vale dizer, divina" (SELIGMANN-SILVA, 2005 p. 35). Sublime como de uma grandeza que "não pode ser abarcada de uma só vez pelos sentidos”. Há uma inadequação entre o objeto e a nossa capacidade de percepção, tanto em termos sensíveis como do ponto de vista intelectual (Idem, p. 35). Como em Burke, também para Mendelssohn a ausência é fonte do sublime, mas "como um desvio de norma e como algo que nos leva para fora de nós mesmos; algo para o qual "não temos palavras"” (Idem, p. 35).

Ocorre uma proximidade do teológico com a arte, no sublime desse filósofo, a obra de arte deve provocar emoções complexas ou mistas, como grotesco, feio, agressivo, para impressionar mais e provocar "um abalo que é gerado por aquilo que não tem limites, pelo sublime espiritual e teológico [...], mas também provocado pelo real-como-morte, como em Burke" (Idem, p. 36).

O grito de perigo pode ser a salvação de uma floresta inteira de sequóias, esse é o intuito do projeto CADS - Cricket-Activated Defense System ${ }^{6}$, onde se conta com a ajuda da própria natureza para cuidar da natureza. O projeto CADS foi desenvolvido em resposta à atividade ilegal de desmatamento na ameaçada floresta de sequóias da Califórnia. Trata-se do emprego modificado de tecnologias originárias dos militares e da indústria, que explora a colaboração inter-espécies na luta para salvar ambientes em extinção, confiando na resposta audível dos grilos à invasão humana e seu posicionamento estratégico nos limites entre as regiões madeireiras. Serve como crítica da lógica hegemônica e como ferramenta tática para uma comunidade sem voz ativa que vive nas proximidades. CADS redefine tecnologias biológicas dentro de um ecossistema político. Grilos são os guardiões ideais de uma área, visto que naturalmente permanecem no perímetro que habitam e emitem sons numa freqüência muito precisa quando se sentem ameaçados pela aproximação de uma espécie invasora. Para evitar

\footnotetext{
${ }^{6}$ CADS. Center for Tactical Magic. Disponível em: http://tacticalmagic.org/CTM/project\%20pages/CADS.htm. Acessado em: 27/08/07
} 
erro, o sistema só é ativado quando uma porção significante da população de grilos emite seu temor, em área relativamente ampla.

Para o sucesso do trabalho CADS conta com a colaboração, não somente entre espécies, mas também do esforço coletivo de uma grande comunidade de pessoas. Esta relação é destacada posteriormente em conferências públicas, nas quais reúnem-se várias disciplinas: arte, criação, biologia, ciência ambiental, etc., vindo a formar um ecossistema acadêmico.

Embora nos pareça que o vazio nada tem a dizer, ele abre caminho para que tudo possa ser elucubrado. Ele está pregnado! E a isso podemos estar atentos.

Voltando à definição do sublime, Imanuel Kant "distingue dois tipos de sublime: o matemático, constituído pela experiência do objeto que não cabe nos parâmetros antropomórficos, e o dinâmico, gerado pelo espetáculo de uma força que não cabe igualmente dentro dos padrões de medida convencionais" (FABRIS, 1996, p. 10). As reflexões de Kant darão estofo a muitos estudos desde então, chegando aos nossos dias como base para novas reflexões.

Eduardo Pérez Soler refletindo sobre o sublime mostra que para Lyotard:

Todo o processo de depuração que caracteriza a arte vanguardista- e que anima uma busca dos elementos "essenciais" e elementares de toda produção artística- tem como conseqüência a necessidade de ir em busca de tudo aquilo que havia sido incapaz de representar a arte precedente. O resultado desses esforços são umas propostas artísticas, cruas e interrogantes, cujos significados vão se tornando incompreensíveis e cujo sentido começa a brilhar pela ausência (SOLER, 1996, p. 23).

Novamente a ausência aparece e é parte importante da reflexão sobre o sublime. Lyotard fala da obra de Barnett Newman que, em 1948, publicou The Sublime is Now. Em suas telas, Newman deixa um vazio que, como diz Clement Greenberg, está pregnado. Newman, como outros artistas alinhados a uma corrente romântica na arte, "buscou inspiração em diversas fontes religiosas que transcendem os limites de uma única seita" (ROSENBLUM, 1993, p. 238). O vazio deixado por Newman em suas pinturas era como que a força primordial criadora.

[...] Newman perseguiu sempre o sublime, o visionário, abordando os mistérios de uma criação, uma divindade, da morte e ressurreição, assim como as referencias paisagísticas de seus títulos - Luz do horizonte, tundrapertencem às experiências dos confins da natureza que para os românticos haviam sido metáforas de mistérios sobrenaturais (IDEM, p. 239).

E Philip Shaw diz:

[...] no caso de Lyotard, "o objetivo do sublime é sustentar uma sensação de choque, de prevenir o leitor/expectador/interpretador de chegar a um entendimento com o que excede a norma. Se o objetivo do Romantismo é de alguma forma incorporar o "senso sublime", o pós-modernismo, em 
contraste, procura manter um senso do sublime como outro, como 'algo' que nunca pode ser "captado" pelo uso de metáforas, símbolos ou conexões verbais". (SHAW, 2006, p. 9)7.

No projeto PigeonBlog, de Beatriz da $\operatorname{Costa}^{8}$, artista portuguesa radicada em New York, em parceria com Cina Hazegh e Kevin Ponto, desenvolve projetos de arte telemática em diálogos com a ciência. Este projeto explora a manipulação e utilização da informação através do uso combinado de computador e um meio de comunicação, a Internet. A artista se apropria de uma tecnologia que inicialmente seria de uso militar, e adapta-a, desenvolvendo um aparato formado por sensores com GPS presos a pombos urbanos, que captam informações da composição química do ar, registrando os níveis de poluição atmosférica, que são transmitidos em tempo real para a Internet. Sua arte atua no sentido de utilizar a tecnologia, transformá-la em objeto de ativismo ambiental. Logo, como ativista que dispõe da tecnologia, tece uma parceria com o animal, o pombo, que é o integrante central desse projeto. A artista, interagindo com o animal, faz uso da tecnologia para conscientizar as pessoas a prestarem atenção na relação homem / animal / meio ambiente. Ela subverte aquele uso inicial do animal como espião transformando-o num agente ambiental.

Nossa incapacidade de definição frente ao vazio que as obras contemporâneas suscitam pode ser a forma como os artistas têm posto em obra o sublime. Todo esse paradoxo, esta falta de palavras para definir os sentimentos que nos assomam, pode ser ponto de partida para investigações frutíferas no sentido de pensar melhor esse tempo atual, nossa forma de viver e a maneira como estamos lidando com a natureza. Nossa necessidade de acumular, de deixar as coisas passarem despercebidas, de não pensarmos no Outro. A colaboração do animal, seus proprietários, técnicos em informática, artistas, formam uma massa pensante que trás à tona o descaso com a natureza e com o próprio ser humano.

Por fim, trago outro trabalho não menos instigante que nos liga à natureza, desta vez, marinha. Trata-se do projeto de Jim Nollman ${ }^{9}$, que está interessado em comunicação inter-espécies, Nollman tem trabalhado em colaboração envolvendo

\footnotetext{
7 "The goal of the sublime is to sustain a sense of shock, to prevent the reader/ viewer/ interpreter from coming to terms with the meaning of that which exceeds the norm. If the aim of Romanticism is somehow to incorporate the 'sense sublime', postmodernism, by way of contrast, seek to retain a sense of the sublime as other, a 'something' that can never be 'interfused' through the use of metaphors, symbols, or verbal connectives".

8 PigeonBlog. Greenmuseum. Disponível em: http://www.pigeonblog.mapyourcity.net/blurb.php . Acessado em: 27/08/07

${ }^{9}$ Field projects. Greenmuseum. Disponível em: http://greenmuseum.org/content/work_index/img_id376_prev_size-0__artist_id-41_work_id-87.html Acessado em: 20/09/07
} 
cientistas, ativistas, artistas e programadores, que usam ferramentas digitais de análise auditiva das mais sofisticadas disponíveis atualmente. Mas não é só gravar o som de baleias. Ele quer uma comunicação através da música. Seu barco de pesquisa está equipado com um sistema de som com microfone e um auto-falante para serem usados embaixo d'água. Ele se mantém a certa distância do local onde as baleias, golfinhos ou toninhas, dentre outras, e começa a tocar. Fica a critério dos animais se aproximarem ou não, mas geralmente se aproximam. Ele costuma tocar uma música com uma estrutura bem dialógica, onde há espaço para o animal. Ele toca um pouco e o animal responde, depois ele toca mais um pouco. $\mathrm{O}$ artista utiliza vários instrumentos, tanto eletrônicos quanto acústicos. Ele entra em contato com a comunidade local, por exemplo, os indígenas habitantes do círculo Ártico, na costa do Canadá. Refere-se a essa experiência como se fosse um telefonema para as baleias, onde escuta as baleias e também transmite. Um interage com o outro, em áreas remotas, com o mínimo de impacto possível.

As pesquisas de Nollman lembram-nos os Românticos que saíam para regiões distantes, exóticas, na tentativa de por em obra o desconhecido, o mistério a ser desvendado. É o misterioso que pregna a obra e faz surgir o sublime, o vazio, um mistério a ser desvendado, oculto a ponto de nos deixar ansiando por respostas que poderão nunca vir.

Cada vez mais percebemos que há um abismo entre as pessoas e entre as pessoas e a natureza. Estamos vivendo numa sociedade de narcisismo e melancolia, como nos fala a psicanalista Luciana Chauí Berlinck,

O gosto pelo efêmero e a perda de referência temporal ao passado e ao futuro; a rápida obsolescência das qualificações para o trabalho, dos valores e das normas de vida e o prestigio do paradigma da moda; a competição como forma de constituição da identidade pessoal; o medo, gerado pela insegurança e pela competição; a perda da autonomia individual sob o poderio do "discurso competente" (a fala dos especialistas); a incapacidade para simbolização e o conseqüente fascínio pelas imagens e pela nova forma da propaganda e da publicidade, que não operam referidas às próprias coisas e sim às suas imagens (juventude, beleza, sucesso, poder) com as quais o consumidor deve identificar-se. Desses traços, a relação com o tempo, e a impossibilidade de simbolização sob $\mathrm{o}$ prestigio das imagens são importantes para a determinação da melancolia. (BERLINCK, 2008, p.34).

Talvez caiba aqui a reflexão do filósofo Emmanuel Levinas (citado em KONESKI, 2007, p. 49-122) quanto ao nosso pensamento para com o Outro. Para Levinas, "Rosto" é o lugar onde o "absolutamente Outro" aparece. Local onde reside a infinitude e a ética (idem, p.87). É como uma epifania, uma revelação sem revelar, algo 
que nos confronta como revelação justamente por não se revelar. Essa ética de "Rosto" nos leva a uma consciência do "não matarás", uma intimação à responsabilidade, e nos abre para uma exterioridade onde o "Outro" é realmente levado em consideração em detrimento do eu. Nossa responsabilidade para com o Outro, para com o todo, passa por uma ética de recuperação de valores que necessita ser buscada incessantemente.

Levinas nos fala do "Há" (il y a) como sendo aquilo que não se mostra, mas deixa vestígios. Onde falta a segurança da compreensão, da luminescência do ser (idem, p.72).

Pois não será exatamente esse ocultamento que os artistas têm posto em obra? Esse ir ao encontro do Outro, estar aberto para ele, travar comunicação, ouvi-lo, prestar atenção, observar, voltar a contemplar, tem sido a ânsia constante e, por mais complexo e repleto de contradição que possa ser, vem sendo um caminho a se trilhar.

Nesse enredamento pode-se, quem sabe, conquistar o almejado desejo de por em obra esse vazio pregnado que, como temos visto, trata-se do paradoxo conceito de sublime.

\section{Referências Bibliográficas:}

AMADO, Guy. O sublime no extremo. Revista Número. São Paulo, n. 8 novembro, 2006.

BECKETT, Wendy. História da pintura. São Paulo: Editora Ática, 2002.

BERLINCK, Luciana Chauí. A Sociedade do Narcisismo e da Melancolia. Cult. São Paulo: ano11, n. 124, mai. 2008.

BERMAN, Marshall. Tudo que é solido desmancha no ar. São Paulo: Companhia Das Letras, 1986. BURKE, Edmund. Uma investigação filosófica sobre a origem de nossas idéias do sublime e do belo. São Paulo: Papirus, 1993.

FABRIS,. Prefácio. In: COSTA, Mario. O Sublime Tecnológico. São Paulo: Experimento, 1995.

KONESKI, Anita. Blanchot e Levinas e a arte do estranhamento. Florianópolis, 236 f., Tese

(Doutorado em Literatura) - Centro de Comunicação e Expreessçao - Universidade Federal de Santa

Catarina. Site: http://www.tede.ufsc.br/teses/PLIT0285-T.pdf

ROSENBLUM, Robert. La pintura moderna y la tradición del romanticismo nórdico de Friedrich a

Rothko. Madri: Alianza. 1993.

SHAW, Philip. The sublime: the new critical idiom. Oxon: Routledge. 2006.

SELIGMANN-SILVA, Márcio. Do delicioso horror sublime ao abjeto e a escritura do corpo. In:

SELIGMANN-SILVA, m. O Local da diferença. São Paulo: Ed. 34, 2005

SOLER, Eduardo Pérez. Ironia versus sublimidade. Lapiz. Madrid: n. 123, 1996.

TARKOVSKI, Andrei. Esculpir o tempo. São Paulo: Martins Fontes, 1990.

VÁZQUEZ, Adolfo Sánchez. Sublime. In: VAZQUEZ, A. S. Convite à Estética. Rio de Janeiro:

Civilização Brasileira, 1999. 


\begin{abstract}
This article approaches historical aspects of the concept of the Sublime and emptiness, and reflects on possible ways of relating it with contemporary artistic projects. The projects studied deal with the mediation of science and technology in the human relationship with nature, and its articulation in contemporary art. It investigates artworks which make use of technological devices to interact with animals and the environment. Amongst the projects examined, are: drawings and photographs by Tim Knowles, The Greenhouse and the Shed project, by Gilles Bruni and Marc Batarit, Cads - Cricket-Activated Defense System project, PigeonBlog by Beatriz da Costa, and the Russian Beluga Project, by Jim Nollman.
\end{abstract}

KEY WORDS: sublime, emptiness, contemporary art

Silvana B. Macêdo

Orientadora

Maria Costa de Araujo

Bolcista voluntária

Acadêmica - Bacharelado em Artes Plásticas 